\title{
STUDI TEORITIS SENYAWA TURUNAN KALKON HIDROKSI SEBAGAI SENSOR KIMIA BERBAGAI ANION
}

\author{
Fitra Perdana ${ }^{1}$, Karna Wijaya ${ }^{2}$ and Ria Armunanto ${ }^{1,2 *}$ \\ ${ }^{1}$ Departemen Kimia, Fakultas Matematika dan Ilmu Pengetahuan Alam, Universitas Gadjah Mada, Sekip \\ Utara, Yogyakarta 55281, Indonesia \\ ${ }^{2}$ Austrian-Indonesian Centre (AIC) for Computational Chemistry, Universitas Gadjah Mada, Sekip Utara, \\ Yogyakarta 55281, Indonesia. \\ *email: ria.armunanto@ugm.ac.id
}

Received 20 October 2018

Accepted 20 December 2018

\begin{abstract}
Abstrak
Studi secara teoritis telah dilakukan untuk mempelajari interaksi senyawa turunan kalkon hidroksi $(\mathbf{C H})$ sebagai sensor kimia dengan anion $\mathrm{F}^{-}, \mathrm{Cl}^{-}, \mathrm{Br}^{-}, \mathrm{CN}^{-}, \mathrm{CH}_{3} \mathrm{COO}^{-}$, dan $\mathrm{NO}_{3}^{-}$. Penelitian ini bertujuan untuk memodelkan struktur molekul senyawa turunan kalkon hidroksi $(\mathbf{C H})$ dan sifat sensornya serta model interaksinya dengan anion dengan metode DFT. Hasil optimasi geometri menunjukkan terjadinya pemanjangan ikatan $\mathrm{O}-\mathrm{H}$ sebesar 0,63-0,85 $\AA$ dengan adanya anion $\mathrm{F}^{-}, \mathrm{CN}^{-}$, and $\mathrm{CH}_{3} \mathrm{COO}^{-}$. Hal ini mengindikasikan terjadinya deprotonasi sensor kalkon hidroksi $(\mathbf{C H})$ oleh anion. Sedangkan interaksi sensor kalkon hidroksi $(\mathbf{C H})$ dengan anion $\mathrm{Cl}^{-}, \mathrm{Br}^{-}$, dan $\mathrm{NO}_{3}{ }^{-}$hanya berupa ikatan hidrogen dengan pemanjangan ikatan O-H sebesar 0,08-0,46 А. Sensor kalkon hidroksi (CH) yang mengalami deprotonasi memiliki energi interaksi yang lebih besar yaitu $-209,37--424,06$ $\mathrm{kJ} / \mathrm{mol}$ dibandingkan sensor yang hanya membentuk ikatan hidrogen yaitu $-98,60--125,59$ $\mathrm{kJ} / \mathrm{mol}$. Sensor yang mengalami deprotonasi mengakibatkan turunnya selisih energi HOMO-LUMO dari -3,94--4,06 eV menjadi -2,62--2,75 eV.
\end{abstract}

Kata kunci: sensor kimia, kalkon hidroksi, anion, DFT

\begin{abstract}
Theoretical study had been carried out to investigate interaction between hydroxy chalcone derivatives $(\mathbf{C H})$ as chemosensors with $\mathrm{F}^{-}, \mathrm{Cl}^{-}, \mathrm{Br}^{-}, \mathrm{CN}^{-}, \mathrm{CH}_{3} \mathrm{COO}^{-}$, and $\mathrm{NO}_{3}{ }^{-}$anions. This study was aimed to design molecular structures of chemosensor hydroxy chalcone $(\mathbf{C H})$ properties for the anions and their interaction models with DFT method. The result of geometry optimization showed $0,63-0,85 \AA$ O-H bond elongation of the hydroxy chalcone was occured by $\mathrm{F}^{-}, \mathrm{CN}^{-}$, and $\mathrm{CH}_{3} \mathrm{COO}^{-}$. It was indicated deprotonation of sensor hydroxy chalcone $(\mathbf{C H})$ by anions. Where as the interaction of the hydroxy chalcone $(\mathbf{C H})$ with $\mathrm{Cl}^{-}$, $\mathrm{Br}^{-}$, and $\mathrm{NO}_{3}{ }^{-}$just formed an hydrogen bond with $0,08-0,46 \AA \mathrm{O}-\mathrm{H}$ bond elongation. Deprotonized sensor hydroxy chalcone (CH) had more energy change of interaction -209,37 $--424,06 \mathrm{~kJ} / \mathrm{mol}$ than sensor which just formed the hydrogen bond $-98,60--125,59 \mathrm{~kJ} / \mathrm{mol}$. Deprotonized sensor caused reduction of the difference of HOMO-LUMO energy from $3,94--4,06 \mathrm{eV}$ to $-2,62--2,75 \mathrm{eV}$.
\end{abstract}

Keywords: chemosensor, hydroxy chalcone, anion, DFT 


\section{Pendahuluan}

Pengembangan senyawa sensor kimia baru yang selektif dan sensitif terhadap anion banyak mendapat perhatian belakangan ini. Hal ini juga disebabkan karena anion berperan penting dan terlibat dalam berbagai proses kimia dan biologi serta perubahan kondisi lingkungan (Shan et al, 2015). Senyawa sensor merupakan senyawa yang digunakan untuk mendeteksi keberadaan spesies lain. Senyawa yang dapat mendeteksi adanya spesies bermuatan negatif secara khusus dikenal sebagai sensor anion. Penggunaan sensor memberikan berbagai keuntungan antara lain sensitivitasnya tinggi dan mudah dalam penggunaan (Li et al, 2010). Senyawa turunan kalkon adalah salah satu senyawa yang berpotensi sebagai sensor. Senyawa kalkon merupakan senyawa yang sangat menarik karena banyak dimanfaatkan berbagai aktivitas biologisnya (Wang et al, 2015). Senyawa turunan kalkon berpotensi sebagai sensor kimia karena strukturnya dapat dimodifikasi dengan menambahkan berbagai gugus substitusi sehingga dapat berinteraksi dengan anion membentuk ikatan hidrogen (Shan et al, 2014).

Kajian secara teoritis melalui perhitungan kimia komputasi telah banyak dilakukan untuk mengkaji interaksi senyawa sensor dan anion. Salah satu keunggulan kimia komputasi adalah dapat memvisualisasikan struktur senyawa sensor dan interaksinya dengan anion (Jin \& Zhang, 2009). Salah satu metode perhitungan kimia komputasi yang banyak digunakan dalam memprediksi interaksi senyawa sensor dan anion adalah metode density functional theory atau teori fungsi kerapatan (DFT). Metode DFT sering digunakan dalam prediksi interaksi sensor dan anion karena metode DFT dapat memberikan hasil yang baik untuk perhitungan yang melibatkan interaksi seperti ikatan hidrogen atau van der Waals (Zhang et al, 2007).

Pada penelitian ini dilakukan studi secara teoritis pengembangan senyawa kalkon turunan hidroksi (CH) sebagai sensor anion dengan menganalisis interaksi sensor (CH) dan aion, energi interaksi, analisis transisi elektronik, dan sifat optikal. Hasil kajian secara teoritis ini diharapkan memberikan informasi yang komprehensif dalam membantu sintesis sensor senyawa turunan kalkon hidroksi (CH) di Laboratorium.

\section{Metode Penelitian}

\section{Bahan kajian}

Bahan kajian yang digunakan pada penelitian ini adalah senyawa turunan kalkon hidroksi $(\mathbf{C H})$ yang tersubstitusi gugus penarik elektron berupa gugus nitro sebagai molekul sensor. Adapun anion yang digunakan pada penelitian ini adalah $\mathrm{F}^{-}, \mathrm{Cl}^{-}, \mathrm{Br}^{-}, \mathrm{CN}^{-}, \mathrm{CH}_{3} \mathrm{COO}^{-}$, dan $\mathrm{NO}_{3}^{-}$. Struktur senyawa turunan kalkon sebagai sensor dan interaksinya dengan anion ditunjukkan pada Gambar 1.<smiles>[R][R]1c(O)ccc(/C=C/C(=O)c2ccccc2)c1[R]</smiles><smiles>[R3]c1[R]([O-])ccc(/C=C/C(=O)c2ccccc2)c1[R]</smiles>

$\mathrm{R}_{1}=\mathrm{H} \mathrm{R}_{2}=\mathrm{C} \mathrm{R}_{3}=\mathrm{NO}_{2}$

Gambar 1. Struktur senyawa turunan kalkon hidroksi $(\mathbf{C H})$ dan interaksinya dengan anion 


\section{Perhitungan komputasi}

Semua perhitungan dilakukan dengan menggunakan perangkat lunak Gaussian 09 (Frisch et al, 2009). Prediksi model interaksi antara senyawa sensor (CH) dengan anion dilakukan dengan cara optimasi geometri kompleks sensor $(\mathbf{C H})$ anion menggunakan metode DFT 6$31 \mathrm{G}(\mathrm{d}, \mathrm{p})$ dengan fungsi densitas B3LYP. Selanjutnya, energi interaksi senyawa sensor $(\mathbf{C H})$ dan anion dihitung dengan metode yang sama. Sifat absorpsi dan energi transisi dari sensor (CH) dan ion sensor $(\mathbf{C H})^{-}$dihitung menggunakan metode TD-B3LYP/6-31G(d,p). Pengamatan pengaruh pelarut dalam sifat optik dalam sistem molekuler dilakukan dengan menggunakan pelarut DMSO dan metanol, dihitung menggunakan polarized continumm model (PCM) dengan metode TD-DFT (Cornard \& Lapouge, 2006). Energi interaksi $\left(\Delta \mathrm{E}_{\text {interaction }}\right)$ dihitung dari selisih antara energi kompleks sensor (CH)-anion (ECH---A-) dan dan total energi sensor $(\mathbf{C H})$ dan anion $\left(\mathrm{A}^{-}\right)$(Vanani \& Alihoseini, 2014).

\section{Hasil dan Pembahasan}

Mekanisme interaksi sensor (CH) dan anion diamati dengan melakukan optimasi geometri terhadap kompleks molekul sensor-anion dengan menggunakan metode density functional theory (DFT). Optimasi geometri dilakukan dengan menjadikan gugus fenol sebagai sisi aktif dan pusat reaksi. Hasil optimasi geometri sensor (CH) dan anion ditunjukkan pada Gambar 2 dan Tabel 1. Interaksi molekul sensor dan anion yang terjadi dapat berupa pembentukan ikatan hidrogen atau terjadinya deprotonasi. Optimasi geometri molekul sensor (CH) dan anion yang menghasilkan jarak antara binding subunit $\mathrm{O}-\mathrm{H}$ dan anion yang kecil dari $3 \AA$ dan pembentukan sudut terbentuk antara binding subunit $\mathrm{O}-\mathrm{H}$ dan anion yang besar dari $110^{\circ}$ menunjukkan terjadinya ikatan hidrogen antara binding unit sensor dengan anion (Steiner \& Desiraju, 1998) (Steiner, 2002) sedangkan terjadinya pemanjangan binding subunit sensor lebih dari $0,4 \AA$ mengindikasikan terjadinya pemutusan ikatan pada binding subunit sensor dan sensor mengalami deprotonasi (Jin, 2012). Terjadinya pemutusan ikatan binding subunit pada sensor akan menyebabkan terjadinya transfer proton intermolekular (IPT) dengan $\mathrm{H}^{+}$terikat pada anion sehingga membentuk kompleks sensor (CH)-anion (Jin, 2011). 


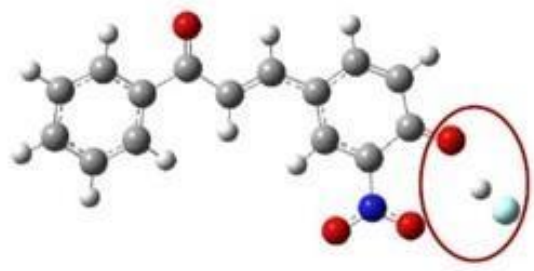

CH---F-

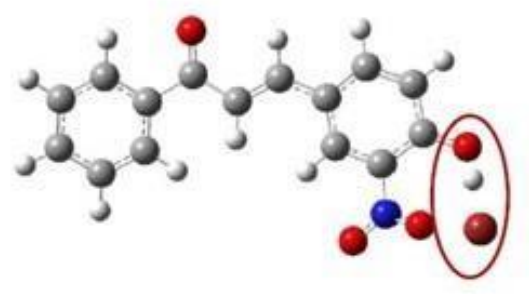

$$
\mathrm{CH}---\mathrm{Br}
$$

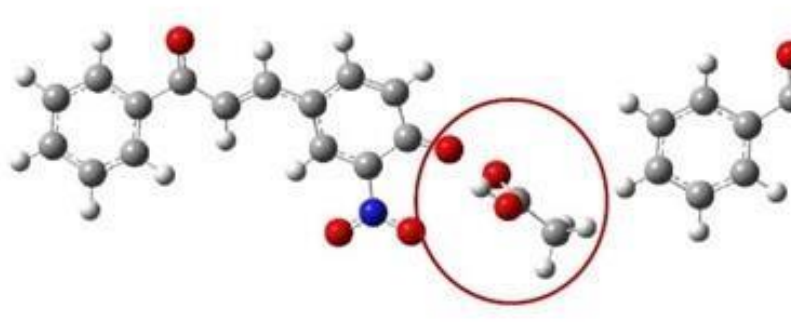

CH--- $\mathrm{CH}_{3} \mathrm{COO}^{-}$

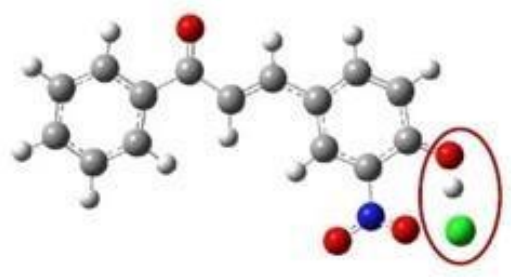

CH--- $\mathrm{Cl}^{-}$

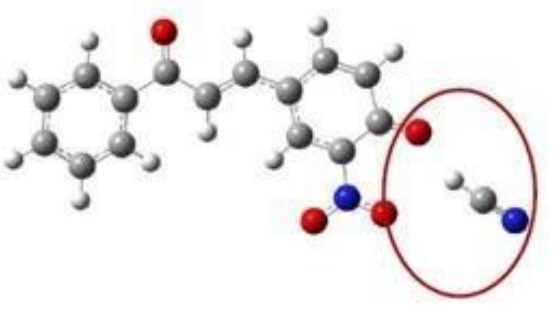

CH--- $\mathrm{CN}^{-}$

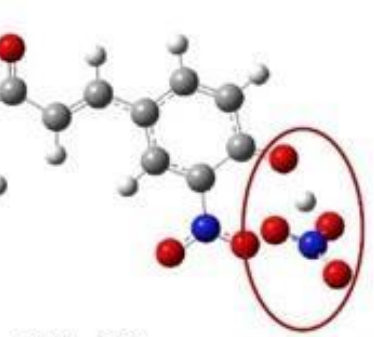

CH--- $\mathrm{NO}_{3}^{-}$

Gambar 2. Optimasi geometri interaksi sensor $(\mathbf{C H})$ dan anion

Struktur senyawa pada sensor $(\mathbf{C H})$ terdapat gugus nitro $\left(-\mathrm{NO}_{2}\right)$ yang merupakan gugus penarik elektron yang kuat pada posisi meta. Pada sensor $(\mathbf{C H})$ panjang ikatan $\mathrm{O}-\mathrm{H}$ sebesar $0,99 \AA$ dan terjadi pemanjangan sebesar 0,$67 ; 0,10$; 0,$08 ; 0,85 ; 0,63$; dan $0,46 \AA$ dengan adanya penambahan anion $\mathrm{F}^{-}, \mathrm{Cl}^{-}, \mathrm{Br}^{-}, \mathrm{CN}^{-}$, $\mathrm{CH}_{3} \mathrm{COO}^{-}$, dan $\mathrm{NO}_{3}^{-}$. Interaksi sensor (CH) dan anion menunjukkan terbentuknya ikatan hidrogen antara gugus $\mathrm{O}-\mathrm{H}$ pada sensor dengan semua anion. Pada interaksi sensor $(\mathbf{C H})$ dengan $\mathrm{F}^{-}, \mathrm{CN}^{-}$ , dan $\mathrm{CH}_{3} \mathrm{COO}^{-}$pembentukan ikatan hidrogen juga terjadi dan juga terjadi deprotonasi senyawa sensor oleh anion sehingga membentuk sensor $(\mathbf{C H})^{-}$dan $\mathrm{H}^{+}$ terikat pada anion. Sedangkan untuk anion $\mathrm{NO}_{3}{ }^{-}$perlu dilihat energi interaksi antara sensor $(\mathbf{C H})$ dan anion untuk memastikan interaksi yang terjadi. Interaksi sensor (CH) dengan anion $\mathrm{Br}^{-}$dan $\mathrm{Cl}^{-}$yang menghasilkan perpanjangan ikatan $\mathrm{O}-\mathrm{H}$ pada sensor (CH) lebih kecil dari $0,4 \AA$ dengan adanya penambahan anion tersebut. Pada penambahan anion $\mathrm{Cl}^{-}$dan $\mathrm{Br}^{-}$pemanjangan hanya terjadi antara $0,04-$ $0,1 \AA$ yang menandakan tidak terjadinya deprotonasi pada sensor. Sehingga interaksi sensor $(\mathbf{C H})$ dengan anion $\mathrm{Cl}^{-}$dan $\mathrm{Br}^{-}$hanya terjadi melalui ikatan hidrogen tanpa adanya deprotonasi pada gugus $\mathrm{O}-\mathrm{H}$. 
Tabel 1. Parameter geometri sensor (CH) dan anion (A)

\begin{tabular}{lccc}
\hline \multicolumn{1}{c}{ Molekul } & $\mathrm{r}_{(\mathrm{O}-\mathrm{H})}(\AA)$ & $\mathrm{r}_{(\mathrm{H}--\mathrm{A})}(\AA)$ & $\theta_{(\mathrm{O}-\mathrm{H}---\mathrm{A})}\left({ }^{\circ}\right)$ \\
\hline $\mathbf{( C H})$ & 0,99 & - & - \\
$(\mathbf{C H})---\mathrm{F}^{-}$ & 1,66 & 0,95 & 161,73 \\
$(\mathbf{C H})---\mathrm{Cl}^{-}$ & 1,09 & 1,73 & 166,45 \\
$(\mathbf{C H})---\mathrm{Br}^{-}$ & 1,07 & 1,92 & 164,93 \\
$(\mathbf{C H})---\mathrm{CN}^{-}$ & 1,84 & 1,10 & 160,04 \\
$(\mathbf{C H})--\mathrm{CH}_{3} \mathrm{COO}^{-}$ & 1,62 & 1,01 & 163,52 \\
$(\mathbf{C H})---\mathrm{NO}_{3}^{-}$ & 1,45 & 1,06 & 163,68 \\
\hline
\end{tabular}

Tabel 2. Energi interaksi sensor (CH) dan anion

\begin{tabular}{lc}
\hline \multicolumn{1}{c}{ Molekul } & $-\Delta \mathrm{E}_{\text {interaksi }}(\mathrm{kJ} / \mathrm{mol})$ \\
\hline $\mathbf{( C H})---\mathrm{F}^{-}$ & 424,06 \\
$(\mathbf{C H})--\mathrm{Cl}^{-}$ & 98,60 \\
$(\mathbf{C H})---\mathrm{Br}^{-}$ & 99,73 \\
$(\mathbf{C H})--\mathrm{CN}^{-}$ & 227,65 \\
$(\mathbf{C H})--\mathrm{CH}_{3} \mathrm{COO}^{-}$ & 209,37 \\
$(\mathbf{C H})---\mathrm{NO}_{3}{ }^{-}$ & 125,59 \\
\hline
\end{tabular}

Proses deprotonasi dapat terjadi apabila interaksi sensor dan anion kuat yang ditunjukkan dengan besarnya energi interaksi sensor dan anion. Energi interaksi hasil perhitungan ditunjukkan pada Tabel 2. Interaksi sensor $(\mathbf{C H})$ dan anion $\mathrm{F}^{-}, \mathrm{CN}^{-}$ , dan $\mathrm{CH}_{3} \mathrm{COO}^{-}$memiliki energi interaksi yang besar. Hal ini mendukung prediksi hasil perhitungan optimasi geometri yang mengindikasikan anion-anion ini menyebabkan sensor mengalami deprotonasi. Sedangkan untuk anion $\mathrm{Cl}^{-}$, $\mathrm{Br}^{-}$dan $\mathrm{NO}_{3}^{-}$energi interaksinya rendah sehingga juga mendukung prediksi anionanion ini tidak menyebabkan terjadinya deprotonasi pada sensor tetapi hanya terjadi ikatan hidrogen antara anion dan sensor.

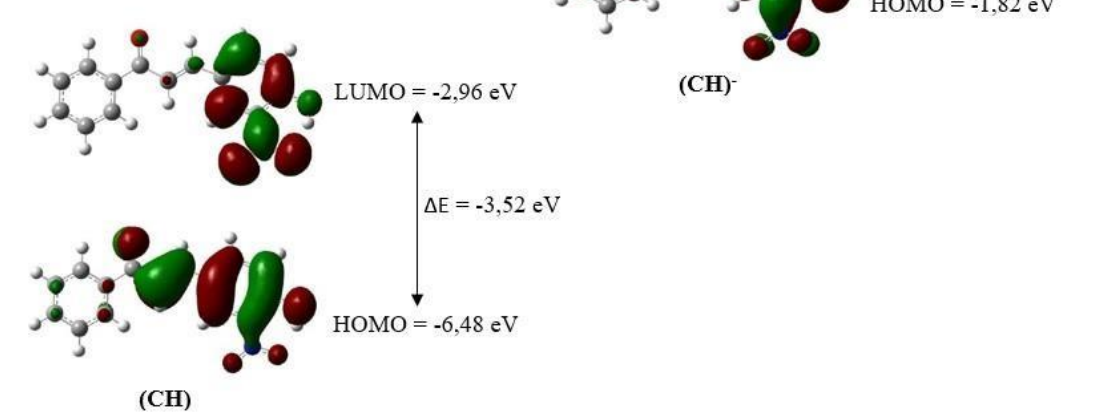

Gambar 3. Perubahan energi HOMO-LUMO sensor (CH) dan ion sensor (CH) 
Transisi elektronik dapat dipelajari dengan analisis Frontier Molecular Orbitals (FMOs) dan perubahan energi HOMO-LUMO. Transisi elektronik dari HOMO ke LUMO menyebabkan terjadinya penyebaran elektron. Bentuk FMOs sensor (CH) dan sensor dalam bentuk ion $(\mathbf{C H})^{-}$ditunjukkan pada Gambar 3. Elektron $\pi$ pada sensor $(\mathbf{C H})$ berasal dari ikatan rangkap

$\mathrm{C}=\mathrm{C}$ pada cincin benzena dan gugus enon $\mathrm{C}=\mathrm{O}$. Sedangkan pada sensor berbentuk ion $(\mathbf{C H})^{-}$elektron $\pi$ juga berasal dari pasangan elektron bebas atom oksigen pada gugus O-H. Pasangan elektron pada oksigen yang bermuatan negatif pada $(\mathbf{C H})^{-}$dapat masuk ke dalam cincin akibat adanya resonansi dengan ikatan rangkap. Pada gambar FMOs (CH), terlihat densitas elektron pada HOMO hanya terdistribusi pada gugus yang terikat dan gugus enon. Adanya eksitasi elektron dari HOMO ke LUMO menyebabkan terjadinya aliran elektron pada LUMO yang tersebar ke seluruh bagian sensor (CH). Aliran elektron pada ion sensor $(\mathbf{C H})^{-}$lebih besar dibandingkan pada kondisi netralnya. Tersebarnya elektron ke seluruh bagian pada ion $(\mathbf{C H})^{-}$ mengindikasikan terjadinya transfer muatan intramolekular (ICT) pada interaksi sensor $(\mathbf{C H})$ dan anion.

Perubahan energi HOMO-LUMO pada sensor $(\mathbf{C H})$ dan ion sensor $(\mathbf{C H})^{-}$yang mengalami deprotonasi juga akan berhubungan dengan sifat optik yang ditunjukkan melalui prediksi spektra UVVis. Puncak prediksi spektra UV-Vis pada ion sensor $(\mathbf{C H})^{-}$terjadi pada panjang gelombang yang lebih besar. Hal ini membuktikan selisih energi HOMOLUMO yang kecil akan menyebabkan adsorpsi UV-Vis akan terjadi pada panjang gelombang yang lebih besar. Pada prediksi transisi elektronik telah dibuktikan selisih energi HOMO-LUMO sensor pada kondisi ion $(\mathbf{C H})^{-}$lebih kecil dibandingkan pada sensor (CH) kondisi netral. Tabel 3 menunjukkan hasil absorpsi UV-Vis sensor $(\mathbf{C H})$ dan ion sensor $(\mathbf{C H})^{-}$yang dihitung menggunakan metode PCM TDB3LYP/6-31G(d,p) dalam pelarut DMSO dan metanol.

Tabel 3. Panjang gelombang absorspi $\left(\lambda_{\text {abs }}\right)$, oscillator strength $(f)$ sensor $(\mathbf{C H})$ dan ion sensor $(\mathbf{C H})^{-}$pada pelarut DMSO dan metanol

\begin{tabular}{ccc|cc}
\hline \multirow{2}{*}{ Pelarut } & \multicolumn{2}{c|}{$(\mathbf{C H})$} & \multicolumn{2}{c}{$(\mathbf{C H})^{-}$} \\
\cline { 2 - 5 } & $\lambda_{\text {abs }}$ & $f$ & $\lambda_{\text {abs }}$ & $f$ \\
\hline DMSO & 338,11 & 0,8031 & 468,83 & 0,4245 \\
Metanol & 336,77 & 0,7069 & 466,37 & 0,4086 \\
\hline
\end{tabular}

\section{Kesimpulan}

Studi secara teoritis yang dilakukan pada penelitian ini memberikan gambaran senyawa turunan kalkon hidroksi (CH) berpotensi sebagai sensor kimia terhadap anion $\mathrm{F}^{-}, \mathrm{Cl}^{-}, \mathrm{Br}^{-}, \mathrm{CN}^{-}, \mathrm{CH}_{3} \mathrm{COO}^{-}$, dan $\mathrm{NO}_{3}{ }^{-}$ . Hasil analisis terhadap interaksi sensor (CH) dengan anion $\mathrm{F}^{-}, \mathrm{CN}^{-}$, dan $\mathrm{CH}_{3} \mathrm{COO}^{-}$ menunjukkan terjadinya deprotonasi dan interaksi dengan anion $\mathrm{Cl}^{-}, \mathrm{Br}$, dan $\mathrm{NO}_{3}{ }^{-}$ menunjukkan hanya terjadi pembentukan ikatan hidrogen.

\section{Daftar Pustaka}

Cornard JP, and Lapouge C., 2006, Absorption Spectra of Caffeic Acid, Caffeate and Their 1:1 Complex with Al(III): Density Functional Theory and Time-Dependent Density Functional Theory Investigations, $J$. Phys. Chem. A., 110; 7159-7166.

Frisch MJ, Trucks GW, Schlegel HB, Scuseria GE, Robb MA, Cheeseman JR, Scalmani G, Barone V, Mennucci B, Petersson GA, Nakatsuji $H$, Caricato $\mathrm{M}$, Li X, Hratchian HP, Izmaylov AF, Bloino J, Zheng G, 
Sonnenberg JL, Hada M, Ehara M, Toyota K, Fukuda R, Hasegawa J, Ishida M, Nakajima T, Honda Y, Kitao $\mathrm{O}$, Nakai $\mathrm{H}$, Vreven T, Montgomery Jr JA, Peralta JE, Ogliaro F, Bearpark M, Heyd JJ, Brothers E, Kudin KN, Staroverov VN, Kobayashi R, Normand J, Raghavachari K, Rendell A, Burant JC, Iyengar S S, Tomasi J, Cossi M, Rega N, Millam JM, Klene M, Knox JE, Cross JB, Bakken V, Adamo C, Jaramillo J, Gomperts R, Stratmann RE, Yazyev O, Austin AJ, Cammi R, Pomelli C, Ochterski JW, Martin RL, Morokuma K, Zakrzewski VG, Voth GA, Salvador P, Dannenberg JJ, Dapprich S, Daniels AD, Farkas Ö, Foresman JB, Ortiz JV, Cioslowski J, Fox D J., 2009, Gaussian 09, Revision A.02, Gaussian, Inc., Wallingford CT.

Jin R, and Zhang J., 2009, Theoretical Investigation of Chemosensor for Fluoride Anion Based on Amidophthalimide Derivatives, Theor. Chem. Acc., 124(3); 225-234.

Jin R., 2011, Theoretical Study of Thiazole Derivatives as Chemosensors for Fluoride Anion, J. Fluor. Chem., 132; 907-914.

Jin R., 2012, Theoretical Study of Chemosensor for Fluoride Anion and Optical Properties of The Derivatives of Diketopyrrolopyrrole, Theor. Chem. Acc., 131; 1-10.

Li G, Zhao G, Han K, He G., 2010, A TDDFT Study on The CyanideChemosensing Mechanism of 8Formyl-7-hydroxycoumarin, $J$. Comput Chem., 32(4); 668-674.

Reisi-Vanani A, and Alihoseini L., 2014, Computational Investigation of The Adsorption of Molecular Hydrogen on The Nitrogen-Doped Corannulene as A Carbon Nano-Structure, Surface Science., 621; 146-151.

Shan Y, Liu Z, Cao D, Liu G, Guan R, Sun N, Wang C, Wang K., 2015, Coumarinic Chalcone Derivatives as
Chemosensors for Cyanide Anions and Copper Ions, Sens. Actuators B Chem., 221; 63-469.

Shan Y, Liu Z, Cao D, Sun Y, Wang K, Chen H., 2014, Nitro Substituted Chalcone Derivatives as QuickResponse Chemosensors for Cyanide Anions, Sensors and Actuators B: Chemical, 198; 15-19.

Steiner T, and Desiraju GR., 1998, Distinction Between The Weak Hydrogen Bond and The Van der Waals Interaction, Chem. Commun., 8; 891-892.

Steiner T., 2002, The Hydrogen Bond in The Solid State, Angew. Chem. Int. Ed., 41; 48-76.

Wang G, Xue Y, An L, Zheng Y, Dou Y, Zhang L, Liu Y., 2015, Theoretical Study on The Structural and Antioxidant Properties of Some Recently Synthesised 2,4,5Trimethoxy Chalcones. Food Chem., 171; 89-97.

Zhang Y, Scanlon LG, Balbuena PB., 2007, Hydrogen Adsorption in Corannulene-Based Materials, Theo. Comput. Chem., 18; 127-166. 